[1]

Wishaw General Hospital, NHS Lanarkshire, Wishaw and Usher Institute of Population

Health Sciences, University of Edinburgh, Edinburgh, UK.

\title{
Progressive respiratory disease: the importance of prognostic conversations and advance care planning
}

The "curative medical model" dominates medical decision-making, but in patients with advanced lung disease it can be redundant and even harmful. Clinicians are reluctant to abandon the traditional approach. However, a steady sea-change is under way not just for potentially life-limiting respiratory disease but also for other long-term conditions, such as heart failure. The sea-change is welcome, but it has been slow in coming for reasons that are complex and entrenched.

The burden of disease arising from lung cancer is well known and health services directed towards palliative care for patients with lung cancer are usually available. However, despite increasing mortality due to chronic obstructive pulmonary disease (COPD) and interstitial lung disease (ILD), the provision of end-oflife care for these conditions is limited. For example, in a recent Swedish study, AHMADI et al. [1] reported that $75 \%$ of patients with oxygen-dependent ILD had breathlessness (not surprisingly), but only $17 \%$ of them had their symptoms controlled. By contrast, $42 \%$ of patients with lung cancer had significant breathlessness, of whom 33\% experienced symptom control. The same discrepancies exist between lung cancer and COPD [2].

Why is this? Why is the effective management of similar degrees of physical and emotional suffering based on their pathogenesis rather than their impact? This is not just a question of unmet need. It is a question of inequity, sometimes amounting to neglect, with its origins in societal as well as professional attitudes and behaviours [3].

In this article, I wish to focus on issues that often stand in the way of making palliative care accessible to the significant number of patients with respiratory disease who need it [4]. These include the pre-eminence of the curative medical model and in turn, our reluctance to engage in prognostic conversations and advance care planning.

\section{The curative medical model}

My personal perspectives on this theme have been strengthened recently by conducting over 140 one-to-one coaching sessions for consultant physicians and surgeons across three hospitals in Scotland. The primary aim of these sessions has been to address the widespread problem of treatment overuse leading to harms and waste $[5,6]$. One of the drivers is the dominance of the curative medical model in medical decisionmaking. It is at the core of the health system and
Cite as: Taylor DR. Progressive respiratory disease: the importance of prognostic conversations and advance care planning. Breathe 2017; 13: 269-273. 
paradoxically works against appropriate good care at the end of life.

The power of curative intent has complex origins. There is the death taboo and the "drive to survive" recently highlighted in "Being Mortal" by Atul Gawande [7]. We do everything to cling on to life and shrink from letting go even when death is inevitable. For doctors, saving lives can be heroic and death means failure. Over-treatment is incentivised by the perception that the risks of omission are greater than the risks of commission. Societal addiction to the curative model is also (not so) subtly reinforced by financial incentives and political agendas [6].

A range of cognitive biases provide doctors with moral justification for treatment overuse [8]. We are therefore slow to avoid or at least minimise what may be futile, burdensome or contrary to the patient's wishes. We hide behind uncertainty and "give the patient the benefit of the doubt". This means that nonbeneficial treatments are widespread in the last 12 months of life [4].

Every treatment has the potential to cause harm, and towards the end of life the balance between benefits and harms shifts steadily (figure 1). Yet somehow in the death-denying, death-defying environment of modern medicine, the principle of "primum non nocere" (first do no harm) has got lost. It should therefore come as no surprise that in one study, quality of life (and death) during terminal illness was inversely proportional to the complexity and cost of medical interventions [9].

Persistence with what is futile also denies patients appropriate palliative care (treatment underuse). Why do we regard palliative care as second best? This is simply not true. In a landmark study, patients with stage 4 lung cancer who received well-organised palliative care had improved outcomes compared with those who received ongoing "curative" treatment, including survival [10]. A similar pattern of outcomes has been observed with nonmalignant respiratory disease [11]

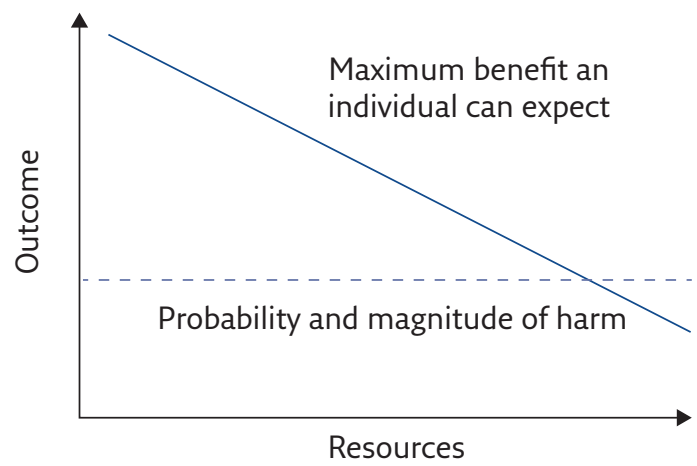

Clinical language Necessary Appropriate Inappropriate Futile Population language High value Low value Negative value

Figure 1 The value of a medical intervention ( $x$-axis) in relation to the diminishing potential for benefit from a "curative" medical intervention that is offered during the last days/weeks/ months of life. Note the unchanging probability and magnitude of harm. First created by Avedis Donabedian (1919-2000). Reproduced from [38] with permission.

\section{COPD and ILD}

All of these considerations are relevant, as well as problematic, in our current approach to advanced COPD and ILD (notably idiopathic pulmonary fibrosis (IPF)). In COPD, post-hospital-discharge "care bundles" focus almost exclusively on preventing further exacerbations with little mention of palliative care [12]. For IPF, the advent of antifibrotic treatments raises significant issues because they represent the attempt to cure. Although these treatments slow disease progression, and this is a legitimate aim, median survival increases from $\sim 2.9$ years [13] by only about 2.5 years [14]. This is not a cure. Even if treatment is successful, the need for palliative treatments is only deferred and should be anticipated. Yet guidelines may [15, 16] or may not [17] give attention to this need.

\section{Prognostic conversations}

The question is: how do we overcome the problems I have highlighted? When the system in which I function is so orientated towards "fix it" medicine, what options do I have? My conclusion is that modifying service priorities towards better endof-life care only gains traction when individual clinicians choose to set aside the curative medical model as the arbiter of best practice. My contract with a patient means providing for their care irrespective of the potential for improved or stabilised organ function even though that is still a legitimate aim.

The starting point is honesty about prognosis. Mortality following a patient's first admission with acute respiratory failure due to COPD was $28 \%$ at 1 year and $48 \%$ at 2 years in one study [18]. In another, the median survival for patients experiencing an acute exacerbation of ILD was 15.5 months from diagnosis and only 2.2 months following the acute exacerbation itself [19]. Yet patients with COPD and ILD rarely have a conversation with their clinician that takes these facts into account $[20,21]$. Is it therefore any surprise that providing for their end-of-life needs is delayed or altogether neglected?

There are a number of myths and misconceptions about prognostic conversations that need to be dispelled.

1) A prognostic conversation is not necessarily the same as an end-of-life conversation, although obviously the two may overlap. I prefer the former term because a prognostic conversation is relevant at any stage in a patient's illness trajectory, including at the time of diagnosis.

2) The word prognosis is popularly understood to mean "how long have I got?". However, notwithstanding the need to consider survival prospects, it is more relevant to think of prognosis in terms of quality rather than quantity. A prognostic conversation means asking "what does the future hold?" and focuses on the impact of progressive 
disease on future quality of life. When someone's health status is deteriorating, considering "what does the future hold?" is a needful prerequisite for improved care.

3) A prognostic conversation based on "what does the future hold?" also accommodates uncertainty with greater ease. Uncertainty is something that we all need to own. William Osler said: "Medicine is a science of uncertainty and an art of probability". SMITH et al. [22] have set out three principles for managing uncertainty: first, normalise it; second, allow the emotions associated with uncertainty to be processed; and third, help patients to live in the here and now more than in the future.

4) The majority of patients and their families prefer to have a prognostic conversation, but expect the clinician to initiate it [23]. For the minority who prefer otherwise, it is not difficult to ask "are you the sort of person who would like to talk about what might lie ahead?" and to respect their answer. Some patients prefer not to have a prognostic conversation, but that is not a reason for denying it to everyone.

5) It is often said that prognostic conversations will adversely affect patient morale, including loss of hope. The evidence suggests differently: a patient's hope is not tied exclusively to survival [24, 25]. Hope is a complex mix of anticipatory perspectives that is about much more than survival. The avoidance of truth telling can be just as damaging to hope - by creating the impression that the future cannot be mentioned! On balance, it is better to disclose the truth rather than withhold it.

\section{Practicalities}

In the context of a busy medical unit, time constraints often mean that a prognostic conversation is difficult. But it is still possible even when time is limited. This is not to advocate poor quality communication, but rather to encourage it to happen!

My personal approach is to ask a patient to reflect on the trends in their health status: "How have things been going for you in the past few months?"; "Compared with 6 months ago, do you think things have changed?" Reflection can then become the basis for anticipation - thinking that explores treatment goals and choices on the assumption that established trends will continue albeit at a variable pace. If the patient lacks capacity, then a similar approach can be used when talking to family members.

For a patient with severe COPD or ILD, the prospect of dying generates not just existential fear, but also the fear of uncontrollable symptoms. For some patients and their families, discussing the mode of dying (often carbon dioxide narcosis) and assuring them that the control of severe dyspnoea will be a treatment priority, provides important reassurance.
Advanced training in communication skills provides for additional benefits [26]. For more on this topic, I recommend the article by RAGLAND et al. [27] and the film "A Good Death" [28].

\section{Advance care planning}

In an age when dying is a process more often than it is a single event, human experience at the end of life often involves an intensifying sense of powerlessness [29]. The time to die is a time when control over my fate is finally ceded. It is in this context that deliberate steps to preserve a person's ability to feel in control provide a meaningful contribution to their well-being. This is one of the reasons for creating an advance care plan (ACP) (table 1). Things go better with planning. In a landmark study, DETERING et al. [30] highlighted that whereas $86 \%$ of patients with an ACP had their wishes and choices fulfilled at the end of life, this was true for only $30 \%$ of patients who did not have an ACP.

However, if I am an advocate for ACPs then, with others, I also recognise that implementation is not easy [31, 32]. I am therefore selective (table 2). My particular concern is to try to ensure quality of care during episodes of acute deterioration (acute exacerbation of COPD and acute exacerbation of ILD). Such events are common and distressing, and may be terminal. Too often patients experience unnecessary physical and psychological harm resulting from discontinuity of care and well-meaning, but inappropriate, medical interventions [34]. Advance care planning including

Table 1 Items for inclusion in an advance care plan

Preferred place of death

Appointment of health/welfare power of attorney

Care arrangements if/when dependent

Will and funeral arrangements

Future crisis management: treatment escalation/limitation boundaries in the event of acute deterioration

Do not resuscitate preference

Information about how and when to use palliative treatments (e.g. opioids, benzodiazepines, "Just in case" prescribing)

End-of-life goals: spiritual, relational ("What matters to me?"; the bucket list)

Table 2 Triggers for initiating an ACP for patients with COPD or ILD 
treatment escalation/limitation plans address these issues.

The entry point for advance care planning is the prognostic conversation [35]. However, although conversations at the time of acute events are critically important, hospitalisation is not the best time for initiating an ACP [36]. The best place is the outpatient clinic. Incorporating an ACP into the educational objectives for a pulmonary rehabilitation programme may be helpful [37].

\section{Conclusion}

Improving quality of care for patients with advanced COPD, ILD or any other progressive respiratory disease requires a paradigm shift. Best supportive care as it is currently experienced is far from best. Palliative care needs to sit alongside curative intent as an equally legitimate professional goal. For individual clinicians, the key is to engage in prognostic conversations not as "breaking bad news", but as a normative element in patient assessment. The question "What does the future hold?" opens the gateway to shared decision making, advance care planning and timely palliative care. These should be at the core of professional training, service provision and management guidelines for chronic progressive respiratory disease.

\section{Conflict of interest}

None declared.

\section{References}

1. Ahmadi Z, Wysham NG, Lundstrom S, et al. End-of-life care in oxygen-dependent ILD compared with lung cancer. Thorax 2016; 71: 510-516.

2. Moens K, Higginson IJ, Harding R. EURO IMPACT: are there differences in palliative care related problems in people living with advanced cancer and eight non-cancer conditions? A systematic review. J Pain Symptom Manage 2014; 48: 660-677.

3. Wolf SM, Berlinger N, Jennings B. Forty years of work on endof-life care: from patient's rights to systemic reform. N EnglJ Med 2015; 372: 678-681.

4. Vermylen JH, Szmuilowocz E, Kahlan R. Palliative care in COPD: an unmet area for quality improvement. Int J Chron Obstruct Pulmon Dis 2015; 10: 1543-1551.

5. Cardona-Morrell M, Kim JCH, Turner RM, et al. Non-beneficial treatments in hospital at the end of life: a systematic review on extent of the problem. Int J Qual Health Care 2016; 28: 456-469.

6. Brownlee S, Doust J, Elshaug AG, et al. Evidence for overuse of medical services around the world. Lancet 2017; 390: 156-168.

7. Gawande A. Being mortal: medicine and what matters in the end. New York, Metropolitan Books, Henry Holt and Company, 2014.

8. Saposnik G, Redelmeier D, Ruff CC, et al. Cognitive biases associated with medical decisions: a systematic review. BMC Med Inform Decis Mak 2016; 16: 138-152.

9. Zhang B, Wright AA, Huskamp HA, et al. Health care costs in the last week of life: associations with end-of-life conversations. Arch Intern Med 2009; 169: 480-488.

10. Temel JS, Greer JA, Muzikansky A, et al. Early palliative care for patients with metastatic non-small-cell lung cancer. N EnglJ Med 2010; 363: 733-742

11. Higginson IJ, Bausewein C, Reilly CC, et al. An integrated palliative and respiratory care service for patients with advanced disease and refractory breathlessness: a randomised controlled trial. Lancet Respir Med 2014; 2: 979-987.

12. Ospina M, Mrklas K, Deuchar L, et al. A systematic review of the effectiveness of discharge care bundles for patients with COPD. Thorax 2017; 72: 31-39.

13. Ley B, Collard HR, King TE. Clinical course and prediction of survival in idiopathic pulmonary fibrosis. $\mathrm{Am} J$ Respir Crit Care Med 2011; 183: 431-440.

14. Fisher M, Nathan SD, Hill C, et al. Predicting life expectancy for pirfenidone and best supportive care in IPF. J Manag Care Spec Pharm 2017; 23: Suppl., S17-S24.
15. National Institute for Health and Care Excellence. Idiopathic pulmonary fibrosis in adults: diagonosis and management. Clinical guideline [CG163]. www.nice.org. uk/guidance/CG163/chapter/Recommendations Date last updated: May 2017.

16. National Institute for Health and Care Excellence Idiopathic pulmonary fibrosis in adults. Quality standard [QS79]. www.nice.org.uk/guidance/qs79 Date last updated: January 2015.

17. Raghu G, Collard H, Egan J, et al. An Official ATS/ERS/ JRS/ALAT statement: idiopathic pulmonary fibrosis: evidencebased guidelines for diagnosis and management. Am J Respir Crit Care Med 2011; 183: 788-824.

18. Chung LP, Winship P, Phung S, et al. Five-year outcome in COPD patients after their first episode of acute exacerbation treated with non-invasive ventilation. Respirology 2010; 15 : 1084-1091.

19. Song JW, Hong SB, Lim CM, et al. Acute exacerbation of idiopathic pulmonary fibrosis: incidence, risk factors and outcome. Eur Respir J 2011; 37: 356-363.

20. Momen N, Hadfield P, Kuhn I, et al. Discussing an uncertain future: end-of-life conversations in COPD: systematic literature review and narrative synthesis. Thorax 2012; 67: 777-780.

21. Tavares $N$, Jarrett $N$, Hunt $K$, et al. Palliative and endof-life care conversations in COPD: a systematic review. ERJ Open Res 2017; 3: 00068-2016.

22. Smith AK, White DB, Arnold RM. Uncertainty: the other side of the prognosis. N Engl J Med 2013; 368: 2448-2450.

23. Wright AA, Zhang B, Ray A, et al. Associations between end-of-life discussions, patient mental health, medical care near death, and caregiver bereavement adjustment. JAMA 2008; 300: 1665-1673.

24. Green MJ, Schubart JR, Whitehead MM, et al. Advance care planning does not adversely affect hope or anxiety among patients with advanced cancer. J Pain Symptom Manage 2015; 49: 1088-1096

25. Apatira L, Boyd EA, Malvar G, et al. Hope, truth and preparing from death: perspectives of surrogate decision makers. Ann Int Med 2008; 149: 861-868.

26. Orford NR, Milnes S, Simpson N, et al. Effect of communication skills training on outcomes in critically ill patients with life-limiting illness. BMJ Support 
Palliat Care 2017; in press [https://doi.org/10.1136/ bmjspcare-2016-001231]

27. Ragland J, Thakore K, Anderson WG. Addressing prognosis in serious illness. Hosp Med Clin 2017; 6: 359-373.

28. PRN films. A Good Death (2012). Trotman P., Taylor D.R., producers. https://vimeo.com/39258619

29. Murray SA, Kendall M, Mitchell G, et al. Palliative care from diagnosis to death. BMJ 2017; 356: j878.

30. Detering KM, Hancock AD, Reade MC, et al. The impact of advance care planning on end of life care in elderly patients: randomised controlled trial. BMJ 2010; 340: 1345-1354.

31. Galushko M, Romotsky V, Voltz R. Challenges in endof-life communication. Curr Opin Support Palliat Care 2012; 6: 355-364.

32. Boddy J, Chenoweth L, McLennan V, et al. It's just too hard! Australian health care practitioner perspectives on barriers to advance care planning. Aus J Primary Health 2013; 19: 38-45.
33. University of Edinburgh. Supportive and Palliative Care Indicators Tool "SPICT". www.spict.org.uk

34. Taylor DR. COPD, end of life and ceiling of treatment. Thorax 2014; 69: 498-500.

35. Seamark D, Blake S, Seamark C, et al. Is hospitalisation for COPD an opportunity for advance care planning? Prim Care ResprJ 2012; 21: 261-266.

36. Burge AT, Lee A, Nicholes $M$, et al. Advance Care Planning education in pulmonary rehabilitation; a qualitative study exploring participant perspectives. Palliat Med 2013; 27: 508-515.

37. Patel K, Janssen DJA, Curtiss JR. Advance care planning in COPD. Respirology 2012; 17: 72-78.

38. Scottish Government. Chief Medical Officer for Scotland annual report 2015/16 realising realistic medicine. Chapter 1: realistic medicine in an international context. Edinburgh, Scottish Government, 2017. www.gov.scot/ Publications/2017/02/3336/4 